\title{
Seasonal and interannual variation in foraging range and habitat of macaroni penguins Eudyptes chrysolophus at South Georgia
}

\author{
K. E. Barlow, J. P. Croxall* \\ British Antarctic Survey, Natural Environment Research Council, High Cross, Madingley Road, \\ Cambridge CB3 0ET, United Kingdom
}

\begin{abstract}
In marine ecosystems, characterisation of the foraging areas and habitats of predators is a key factor in interpreting their ecological role. We studied the foraging areas of the macaroni penguin Eudyptes chrysolophus at Bird Island, South Georgia, throughout the breeding seasons of 1999 to 2001 using satellite tracking. We investigated differences in foraging ranges and characteristics between different stages of the breeding season, between sexes, between years and between individuals. During incubation, on foraging trips of 10 to $26 \mathrm{~d}$, both sexes travelled long distances from Bird Island (male average $=572 \mathrm{~km}$; female average $=376 \mathrm{~km}$ ) in a north-westerly direction towards the Maurice Ewing bank; some individuals, particularly males, travelled to forage in the Polar Frontal Zone. In contrast, during the chick-rearing period, both sexes mainly foraged relatively close (average $62 \mathrm{~km}$ ) to South Georgia over the continental shelf. Foraging trip characteristics differed between males and females during chick rearing: females travelled further on average and on more direct trips. During chick rearing, males and females on longer foraging trips covered greater distances and travelled further from Bird Island. There were no interannual differences in characteristics of foraging trips, although sex differences in some parameters varied between years. The bearings of chick-rearing foraging trips were non-random and most were in a north-westerly direction. Variation, both intra- and inter-individual, in bearings of foraging trips was high. Travel speeds were slower during foraging trips in the chick-rearing period than during incubation, probably relating to the differences in distances travelled. The stage of the breeding season, associated constraints on the penguins at different stages, and sex were important in determining variation in foraging range and characteristics in macaroni penguins, but year and individual effects were relatively unimportant.
\end{abstract}

KEY WORDS: Satellite tracking $\cdot$ Chick rearing $\cdot$ Incubation · Southern Ocean · Polar Front

\section{INTRODUCTION}

Knowledge of the diet, energy requirements and foraging range of marine top predators, ideally in relation to the distribution and abundance of their main prey, is essential for understanding their feeding ecology and foraging strategies and determining their role in food webs. These make important contributions to our understanding of the structure and functioning of large marine ecosystems. In the Southern Ocean, penguins are one of the most important groups of consumers (Croxall \& Lishman 1987). Their diet and energy requirements

${ }^{*}$ Corresponding author. E-mail: j.croxall@bas.ac.uk are relatively well known, at least during the breeding season, but their foraging ranges are poorly understood. These have been inferred chiefly from travel speeds and time budgets (e.g. Croxall et al. 1984, Croxall \& Prince 1987, Trivelpiece et al. 1987), or deduced from observations at sea of birds of unknown status and/or origin (e.g. Stahl et al. 1985, Hunt et al. 1992, Veit et al. 1993, Trathan et al. 1998). The relatively recent developments in miniaturisation and hydrodynamic design of instruments for satellite tracking has made the characterisation of penguin foraging ranges feasible. Several penguin species have now been studied (e.g. Jouventin et al. 1994, Kerry et al. 1995, Bost et al. 1997, Hull et al. 1997, Stokes et al. 1998, Kooyman et al. 1999), but most 
investigations have been restricted to only part of the breeding season and often to a single year.

The macaroni penguin Eudyptes chrysolophus, the most abundant penguin species worldwide (Woehler 1993), is one of the principal marine predators in the South Georgia area of the Southern Ocean, where an estimated two-and-a-half million pairs breed (Trathan et al. 1998). The foraging behaviour of this top predator, whose diet is principally the Antarctic krill Euphausia superba (Croxall \& Prince 1980, Croxall et al. 1997), is likely to have a large influence on the structure and function of ecosystem interactions in the South Georgia region. Currently, there are limited data on the distribution and behaviour of macaroni penguins at sea (Hunt et al. 1992, Green et al. 1998, Trathan et al. 1998). Previous estimates of its spatial distribution relied on extrapolation of at-sea data derived from ship observations carried out during very limited time periods and over restricted areas (Hunt et al. 1992). In addition to the normal biases in at-sea distribution data (e.g. van Franeker 1994), because macaroni penguins dive most actively during daytime (Croxall et al. 1993, Green et al. 1998), the small proportion of time spent at the surface during daylight hours is likely to lead to substantial under-recording.

In this study we used satellite tracking to investigate for the first time the foraging behaviour of macaroni penguins during both of the main stages of the breeding season (Fig. 1) at South Georgia: incubation and chick rearing. We addressed 4 questions: (1) Are

\begin{tabular}{|c|c|c|c|}
\hline & MALE & FEMALE & \\
\hline November & Courtship & Courtship & \\
\hline December & $\begin{array}{l}\text { Incubates } \\
\text { At sea } \\
\text { Incubates }\end{array}$ & $\begin{array}{l}\text { Incubates } \\
\text { Incubates } \\
\text { At sea }\end{array}$ & 2nd egg laid \\
\hline January & Brood/guard & Feeds chick & Chick hatches \\
\hline February & Feeds chick & Feeds chick & Chick creches \\
\hline March & $\begin{array}{l}\text { At sea } \\
\text { Moult }\end{array}$ & $\begin{array}{l}\text { At sea } \\
\text { Moult }\end{array}$ & Chick fledges \\
\hline April & At sea & At sea & \\
\hline
\end{tabular}

Fig. 1. Eudyptes chrysolophus. Breeding cycle at Bird Island, South Georgia there differences in the foraging ranges, habitat use and characteristics of foraging trips between the incubation period and the chick-rearing period? During incubation, macaroni penguins undertake long (approximately 2 wk: Williams \& Croxall 1991) incubation shifts followed by foraging trips of similar duration. These long trips are used to acquire resources for, or to recover from, fasting in incubation shifts during which penguins may lose more than $25 \%$ of their body mass (Croxall 1984). In the chick-rearing period, however, the principal constraint is the need to return to the colony at regular intervals to feed their chick, particularly for female penguins during the guard stage. (2) Are there differences in foraging ranges and characteristics of foraging trips between the sexes? In the sexually dimorphic macaroni penguin there is an unequal division of labour during chick rearing. In the guard period, only the female provisions the small chick; in the crèche period, both male and female penguins provision the much larger chick. (3) Are there interannual differences in foraging ranges and foraging trips, and can these differences be related to the diet composition and food availability during the chick-rearing period? (4) Is there significant inter- and/or intra-individual variation in characteristics of foraging trips during chick rearing?

\section{MATERIALS AND METHODS}

Study site. The study was carried out at Bird Island, South Georgia $\left(54^{\circ} 00^{\prime} \mathrm{S}, 38^{\circ} 02^{\prime} \mathrm{W}\right)$. Deployments were carried out from 29 December 1998 to 16 February 1999, referred to as the 1999 season; from 2 December 1999 to 19 February 2000, referred to as the 2000 season; from 3 to 29 December 2000, referred to as the 2001 season. Breeding birds at the Fairy Point macaroni penguin colony, a small study colony of approximately 580 breeding pairs, were marked early during the breeding season; a number was painted on the chest feathers with black dye so that they could be identified individually. Study birds were selected randomly, after excluding nests in the very centre of the colony, access to which would have caused undue disturbance. Devices were only deployed on 1 partner at a nest at one time, never on both simultaneously, and on different individuals across years.

Deployment of devices. Marked penguins were captured at the colony during the incubation period in December 1999 and 2000 and during the chick-rearing period in January and February 1999 and 2000. During the incubation period, marked birds about to leave the nest to go to sea on their long foraging trip were removed from nests at which both partners were present, to ensure that incubation continued once the bird 
was captured. During chick rearing, when possible, marked birds were captured once they had fed the chick and left the nest to start to return to sea, in order to reduce disturbance. A platform terminal transmitter (ST-10 PTT; Telonics, USA, packaged by Sirtrack, New Zealand) was attached to the lower medial portion of the back of the penguin using waterproof Tesa ${ }^{\circledR}$ tape and quick-set epoxy resin following the methods described by Wilson et al. (1997). The PTTs (mass $85 \mathrm{~g}$, dimensions $95 \times 42 \times 20 \mathrm{~mm}$, antenna at $90^{\circ}$ ) were streamlined at the front of the device to reduce hydrodynamic drag (Culik et al. 1994). Each bird was sexed by bill measurements following Williams \& Croxall (1991). Sex was confirmed where necessary by the pattern of attendance at the nest. The attachment procedure took $<20 \mathrm{~min}$ in total, and penguins were then released close to their nest site. Instruments were attached to male and female penguins on long trips between incubation shifts, to female penguins during the guard period of chick rearing, and to male and female penguins during the crèche period of chick rearing. During incubation, devices were deployed for 1 foraging trip per individual (from 10 to $17 \mathrm{~d}$ ). During chick rearing, devices were deployed for 1 to 6 foraging trips per individual (about 2 to $12 \mathrm{~d}$ ).

Location data and analysis. Locations of penguins carrying devices were provided by the ARGOS system and assigned to one of 6 classes $(3,2,1,0, A, B)$ depending on their accuracy. Classes 1 to 3 gave positions accurate to within 1 to $2 \mathrm{~km}$, and Class 0 gave positions accurate to $3.8 \mathrm{~km}$ on average; only these 4 classes were used in analysis (as in Boyd et al. 1998). To verify the location data, the speed $\left(\mathrm{km} \mathrm{h}^{-1}\right)$ travelled between adjacent locations within each foraging trip was calculated. If speed from a previous location was $>10 \mathrm{~km} \mathrm{~h}^{-1}$, this location was deleted. Estimated swimming speed for macaroni penguins ranges from 7.0 to $8.2 \mathrm{~km} \mathrm{~h}^{-1}$ and is $7.5 \mathrm{~km} \mathrm{~h}^{-1}$ on average (Clarke \& Bemis 1979, Brown 1987). The cut-off speed of $10 \mathrm{~km} \mathrm{~h}^{-1}$ was used to avoid inclusion of aberrant data points and over-estimation of distances travelled during foraging trips; $<1 \%$ of locations were removed during this verification procedure.

The trip duration ( $\mathrm{h}$ or $\mathrm{d}$ ), total distance travelled $(\mathrm{km})$, maximum distance reached from Bird Island (range in $\mathrm{km}$ ) and the elongation coefficient (elongation = distance/range, following Guinet et al. 1997) were calculated for each foraging trip recorded. Low elongation coefficients of $\sim 2$ indicate that penguins travelled in approximately a straight line, suggesting direct trips; higher elongation coefficients indicate less direct trips. In the calculation of the above trip parameters, we assumed that penguins travel in a straight line between consecutive locations. The calculations did not account for time spent below the surface of the water. Foraging trips during the chick-rearing period that provided $\leq 3$ locations were not used in analysis of trip parameters. Foraging trip durations during the chick-rearing period were compared to data collected from the same colony in another study from penguins carrying small radio transmitters (median duration $=13.9 \mathrm{~h}, \mathrm{n}=1525,87 \%$ of trips less than $48 \mathrm{~h}$ in duration: Barlow \& Croxall 2001).

Foraging trips recorded during chick rearing were divided into short and long trips: short trips were those that lasted $<24 \mathrm{~h}$ and therefore contained only 1 'day' of foraging; long trips were those that lasted $>24 \mathrm{~h}$ and therefore contained more than 1 'day' of foraging. Diving data from macaroni penguins suggest that most foraging activity is diurnal (Croxall et al. 1993, Green et al. 1998). The division between short and long trips was made in order to investigate differences in foraging trip parameters between penguins that remained at sea for 1 daylight foraging period and those that remained at sea for $>1$ daylight foraging period.

The direction of each foraging trip was calculated as the bearing in an anti-clockwise direction from Bird Island to the location at the maximum range reached during the trip. Travelling speed was estimated for each day and each night period of each foraging trip by summing the total distance travelled and total time between the locations recorded nearest to sunrise and sunset on each day. Mean day and night travelling speeds and overall mean speed were then calculated for each foraging trip. Calculated speeds were transformed using the square-root transformation to achieve normality and compared between day and night during the different stages of the breeding season.

Foraging trip parameters were compared between years (1999 versus 2000), between the sexes and between trips of different lengths (short versus long) using Student's $t$-tests or ANOVAs as appropriate. Data were transformed where necessary to conform to the assumptions of ANOVA (Zar 1984). Foraging ranges of penguins during different parts of the breeding season, during different years and by males and females were also examined by plotting foraging density distributions. Percentage frequency tables of the distribution of locations within $0.1^{\circ}$ squares (approximately $11 \times 9 \mathrm{~km}$ ) were constructed for each stage, year or sex. Contour plots of the distribution densities were created using a linear spline interpolation of the data in Matlab (MathWorks).

Circular statistics (Zar 1984) were used to test whether chick-rearing foraging trip bearings were randomly distributed from Bird Island. For penguins for which $>2$ foraging trips were recorded, interindividual differences in trip bearing were investigated using ANOVA. Analyses were carried out using SAS/STAT (SAS Institute). 


\section{RESULTS}

A total of 13 deployments was made on male and female penguins during incubation in the 2000 and 2001 seasons (Table 1). A total of 50 deployments was made on females during the guard period of chick rearing and males during the crèche period of chick rearing in the 1999 season, females during the guard period, and males and females during the crèche period in the 2000 season (Table 1). In addition to the deployments given in Table 1, 8 devices (14\% of all deployments) were deployed but not recovered. During the chick-rearing period, 4 devices were lost from females in 1999, 1 from a female in 2000, and 1 from a male in 2000. All nests subsequently failed. During incubation, 1 device was lost from a female in 2000 and 1 from a female in 2001, and both nests failed. For each foraging trip recorded, the number of locations per day after processing of the data had been carried out varied from 1 to 14 (mean $=5.3 \mathrm{~d}^{-1}, \mathrm{SD}=2.6, \mathrm{n}=136$ ). The number of locations recorded varied through the day, with peaks at around midnight and 09:00 $\mathrm{h}$ and a period of $2 \mathrm{~h}$ in the middle of the day (14:00 to 16:00 h) in which very few locations were recorded (Fig. 2). Duration between locations used in the analysis varied between 1 and $20 \mathrm{~h}$ overall (e.g. 1999 season chickrearing locations: mean time between locations $=10.3 \mathrm{~h}$, range 0.9 to $18.8 \mathrm{~h}, \mathrm{n}=139$ ).

\section{Incubation foraging trips}

The foraging trip duration of male penguins on the first long trip during incubation lasted 16 or $17 \mathrm{~d}$ in the 2000 season $($ mean $=16.5 \mathrm{~d}, \mathrm{SD}=0.6, \mathrm{n}=4)$ and 17 to $26 \mathrm{~d}$ in the 2001 season (mean $=21 \mathrm{~d}, \mathrm{SD}=3.7$, $\mathrm{n}=3$ ). The foraging trip duration of female penguins on the long trip following their incubation shift lasted from 10 to $15 \mathrm{~d}$ in the 2000 season (mean $=12.5 \mathrm{~d}$, $\mathrm{SD}=2.4, \mathrm{n}=4)$ and 11 and $13 \mathrm{~d}$ in the 2001 season $(\mathrm{n}=2)$.

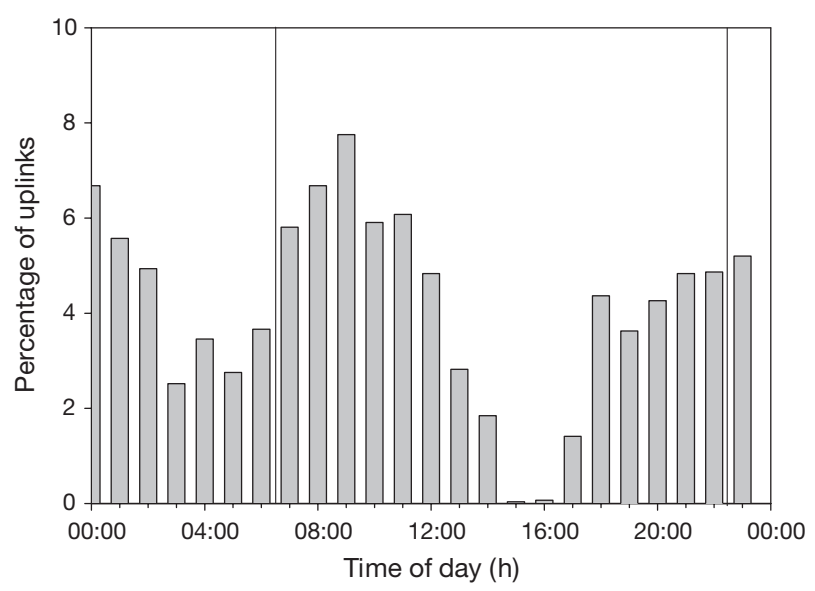

Fig. 2. Eudyptes chrysolophus. Distribution of uplinks recorded from satellite tags throughout the day from all instrumented penguins ( $n=2978$ uplinks). The 2 vertical lines represent the approximate sunrise and sunset times for the period of the study

The long trips undertaken by males and females during the incubation period covered very long distances. In 2000, 6 of the 8 tracked birds reached the area of the Maurice Ewing Bank (MEB) NW of South Georgia (Table 2, Fig. 3). In 2001, males travelled even further beyond the MEB and to the east of it, whereas the 2 females tracked followed a similar pattern to that seen in 2000 (Table 2, Fig. 3). The percentages of time spent across the Polar Front (PF) were calculated for male and female penguins in each year (Fig. 3, Table 3); males spent a greater proportion of time beyond the PF than females. The mean calculated travelling speed for all incubation trips was $4.2 \mathrm{~km} \mathrm{~h}^{-1}$ both in 2000 and 2001. In 2000, calculated travelling speeds were greater during the day (mean $=4.6 \mathrm{~km} \mathrm{~h}^{-1}, \mathrm{SD}=2.1, \mathrm{n}=100$ ) than at night (mean $=3.9 \mathrm{~km} \mathrm{~h}^{-1}, \mathrm{SD}=2.3, \mathrm{n}=97$ ) during incubation trips $(t=2.72, \mathrm{p}=0.0072, \mathrm{df}=195)$. In 2001, calculated travelling speeds did not differ during the day (mean $=3.8 \mathrm{~km} \mathrm{~h}^{-1}, \mathrm{SD}=2.0, \mathrm{n}=85$ ) and night (mean $=4.6 \mathrm{~km} \mathrm{~h}^{-1}, \mathrm{SD}=3.2, \mathrm{n}=81$ ) during incubation trips $(t=1.70, \mathrm{p}=0.09, \mathrm{df}=164)$.

Table 1. Eudyptes chrysolophus. Number of penguins instrumented during the 1999 to 2001 seasons at each stage of the breeding season for each sex, and the number of foraging trips recorded for each group

\begin{tabular}{|c|c|c|c|c|c|c|}
\hline \multirow[t]{2}{*}{ Stage } & \multicolumn{2}{|c|}{1999} & \multicolumn{2}{|c|}{2000} & \multicolumn{2}{|c|}{2001} \\
\hline & Individuals & Trips & Individuals & Trips & Individuals & Trips \\
\hline Incubation (male) & - & - & 4 & 4 & 3 & 3 \\
\hline Incubation (female) & - & - & 4 & 4 & 2 & 2 \\
\hline Guard (female) & 17 & 44 & 12 & 38 & - & - \\
\hline Crèche (male) & 10 & 24 & 6 & 13 & - & - \\
\hline Crèche (female) & - & - & 5 & 9 & - & - \\
\hline Total & 27 & 68 & 31 & 68 & 5 & 5 \\
\hline
\end{tabular}


Table 2. Eudyptes chrysolophus. Foraging trip range, distance, elongation coefficient and calculated speed of males and females during incubation trips and all chick-rearing trips recorded in all years

\begin{tabular}{|c|c|c|c|c|c|c|c|c|c|}
\hline \multirow[t]{2}{*}{ stage } & \multirow[t]{2}{*}{$\mathrm{n}$} & \multicolumn{2}{|c|}{ Range (km) } & \multicolumn{2}{|c|}{ Distance $(\mathrm{km})$} & \multicolumn{2}{|c|}{$\begin{array}{l}\text { Elongation } \\
\text { coefficient }\end{array}$} & \multicolumn{2}{|c|}{$\begin{array}{c}\text { Calculated speed } \\
\qquad\left(\mathrm{km} \mathrm{h}^{-1}\right)\end{array}$} \\
\hline & & Mean & Range & Mean & Range & Mean & Range & Mean & Range \\
\hline Incubation (male) & (7) & 572 & $508-643$ & 1827 & $1551-2164$ & 3.2 & $2.8-3.6$ & 4.2 & $3.6-5.1$ \\
\hline Incubation (female) & (6) & 376 & $251-486$ & 1236 & $974-1608$ & 3.3 & $2.7-4.0$ & 4.4 & $3.3-5.6$ \\
\hline Chick-rearing & (95) & 62.1 & $2.8-336$ & 198 & $14-1379$ & 3.4 & $1.7-12.4$ & 3.5 & $0.4-6.9$ \\
\hline
\end{tabular}

\section{Chick-rearing foraging trips}

Foraging trip duration during the chick-rearing period varied from 0.5 to $358 \mathrm{~h}$ (median $=18.6 \mathrm{~h}, \mathrm{n}=128$ ) and $80 \%$ of trips lasted less than $48 \mathrm{~h}$ in duration. There was no significant difference in trip duration between these birds and the comparison group of birds carrying small radio transmitters (Mann-Whitney $W=12.6 \times 10^{5}, \mathrm{p}=0.22$ ).

Foraging trip parameters were calculated for 95 of the 128 trips recorded from 50 individuals during chick rearing ( $74 \%$ of recorded trips). The median number of a

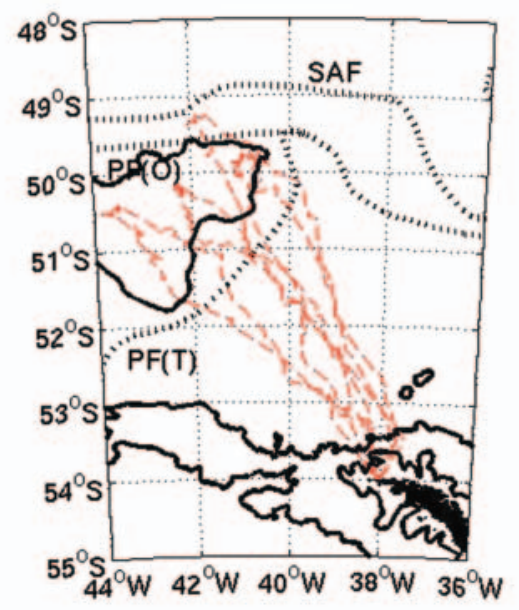

c

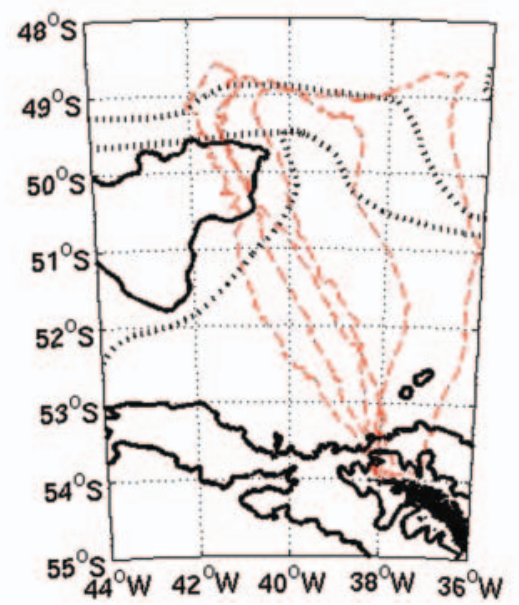

b

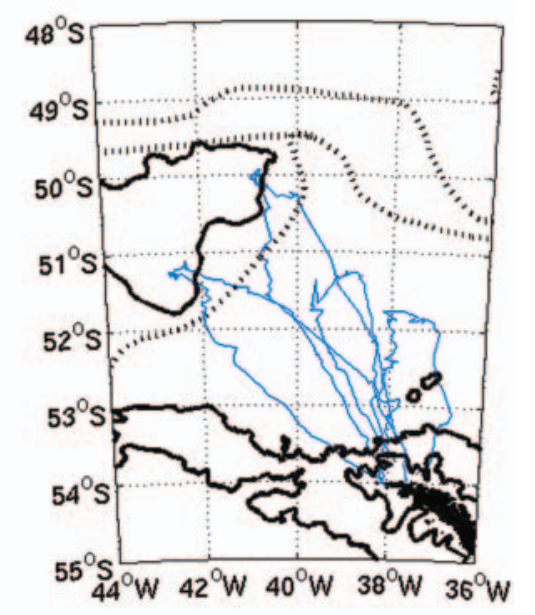

d

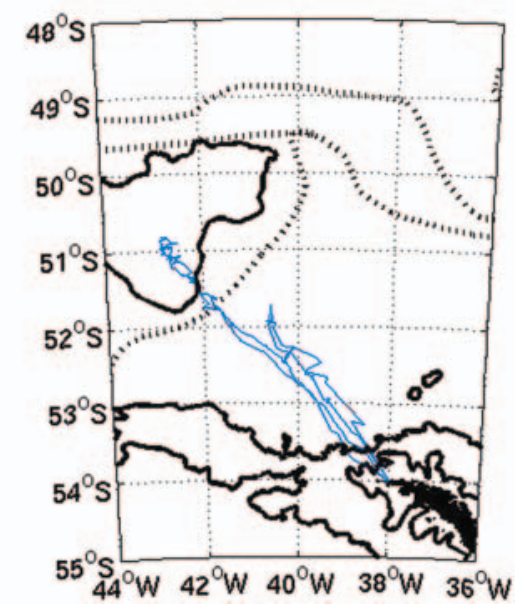

Fig. 3. Eudyptes chrysolophus. Tracks of long foraging trips following incubation shifts by (a) males in 2000 (red dashed lines), (b) females in 2000 (blue continuous lines), (c) males in 2001, (d) females in 2001. Maps show South Georgia, the 200 and $2000 \mathrm{~m}$ bathymetric contour lines (representing the continental shelf around South Georgia and the Maurice Ewing Bank to the northwest) and the approximate positions of the Subantarctic Front (SAF) and the Polar Front (PF). Two positions of the PF are shown: $\mathrm{PF}(\mathrm{O})$ follows Orsi et al. (1995), PF(T) follows Trathan et al. $(1997,1999)$ 
Table 3. Eudyptes chrysolophus. Percentage of time spent beyond the Polar Front by males and females during the foraging trips following incubation shifts in 2000 and 2001 seasons

\begin{tabular}{|lll|}
\hline Sex & 2000 & 2001 \\
\hline Males & 42 & 65 \\
Females & 20 & 25 \\
\hline
\end{tabular}

trips recorded per individual was 2 (range 1 to 6 ). A total of 61 foraging trips was analysed from the guard period (22 short and 39 long trips) and 34 from the crèche period (16 short and 18 long trips) of chick rearing in the 2 years. Foraging trip duration ranged from 0.5 to $23.7 \mathrm{~h}$ on short trips and from 26.2 to $358 \mathrm{~h}$ on long trips.

Distances and ranges covered during chick-rearing foraging trips were much shorter than during the preceding incubation trips (Table 2, Fig. 4). On most foraging trips, penguins were confined to the continental shelf of South Georgia, within the $2000 \mathrm{~m}$ depth contour; many penguins remained on the shelf, within the $200 \mathrm{~m}$ depth contour (Fig. 4). The density distributions of all locations recorded during incubation trips and chick-rearing trips are quite different (Fig. 5): during chick rearing the main concentration of locations was over the continental shelf whereas during incubation the main concentration of locations was over the MEB. The mean calculated travelling speed for all chick-rearing trips was $3.8 \mathrm{~km} \mathrm{~h}^{-1}$. Calculated travelling speeds did not differ between day (mean $=3.5 \mathrm{~km} \mathrm{~h}^{-1}$, $\mathrm{SD}=2.3, \mathrm{n}=147$ ) and night (mean $=4.3 \mathrm{~km} \mathrm{~h}^{-1}, \mathrm{SD}=3.0$, $\mathrm{n}=65)$ during chick-rearing trips $(t=1.56, \mathrm{p}=0.12$, $\mathrm{df}=210$ ). Overall, travelling speeds were higher during incubation than during chick rearing (Table $2 ; t=2.64$, $\mathrm{p}=0.0084$, df $=573$ ).

There were differences in trip characteristics between short and long trips. Distance travelled $(t=8.5, \mathrm{df}=93$, $\mathrm{p}=0.0001)$, range $(t=7.9, \mathrm{df}=93, \mathrm{p}=0.0001)$ and trip a

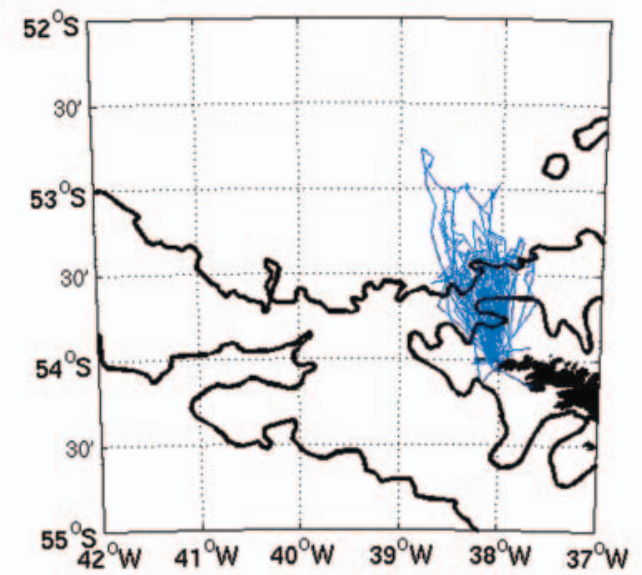

C

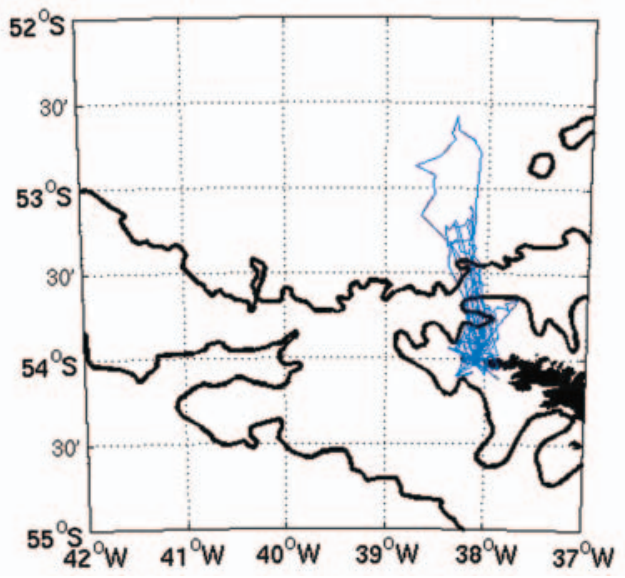

b

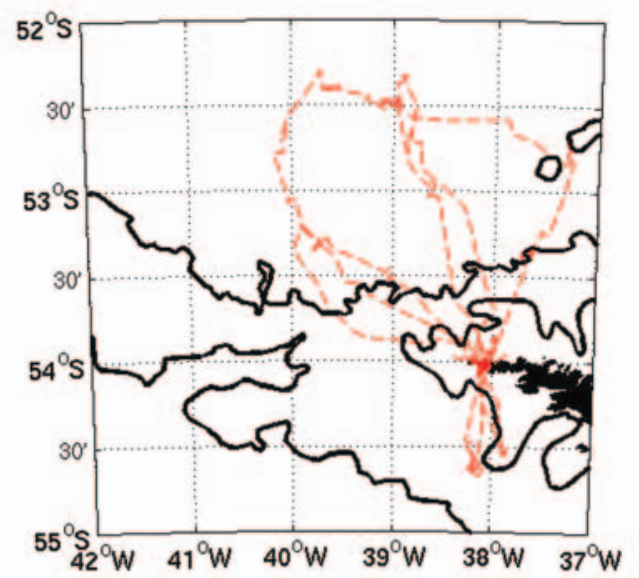

d

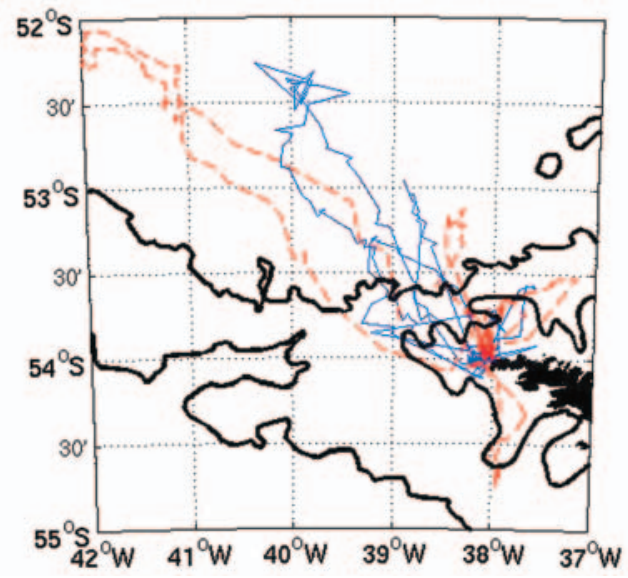

Fig. 4. Eudyptes chrysolophus. Tracks of foraging trips made during (a) guard period and (b) crèche period of chick rearing in 1999, and (c) guard period and (d) crèche period of chick rearing in 2000. Tracks of male penguins are shown as red dashed lines,

those of females as blue continuous lines. Maps show South Georgia and the 200 and 2000 m bathymetric contour lines 
a

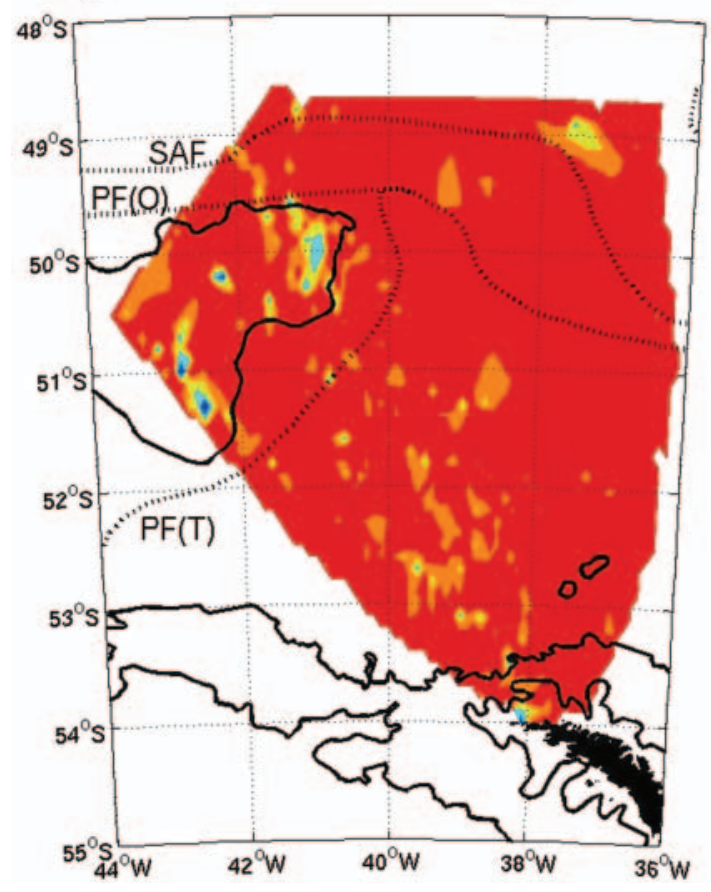

b

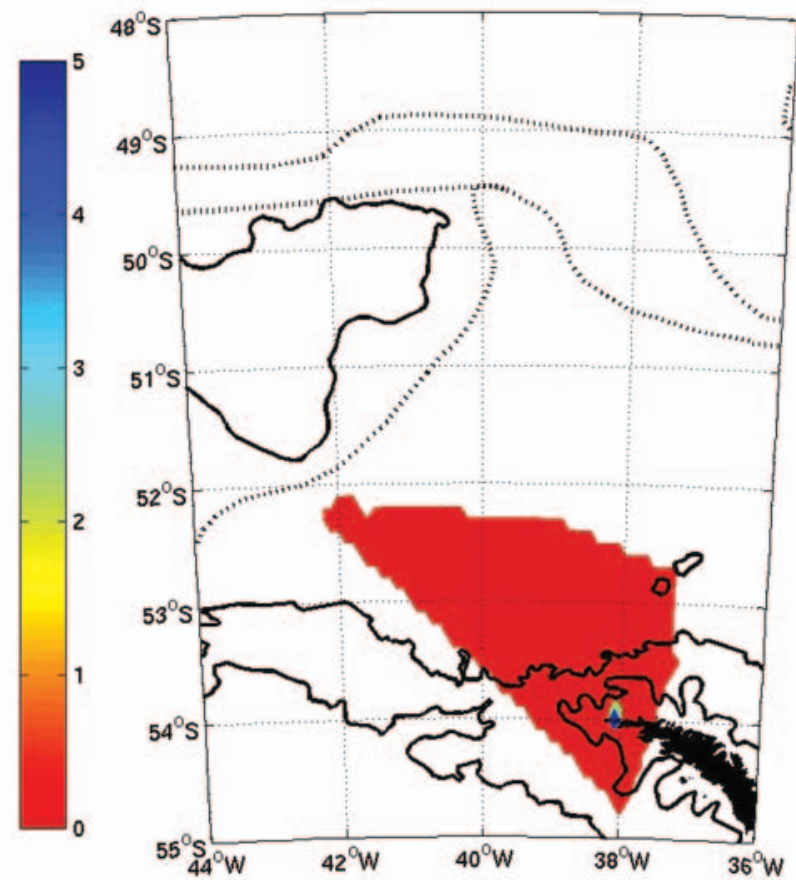

Fig. 5. Eudyptes chrysolophus. Density distributions during incubation (a) and chick-rearing (b) periods. Maps show South Georgia, the 200 and $2000 \mathrm{~m}$ bathymetric contour lines (representing the continental shelf around South Georgia and the Maurice Ewing Bank to the northwest) and the approximate positions of the SAF and PF. Density distributions are constructed from contour plots of 5 contours with a linear spline interpolation. Red represents the least dense areas, blue the most dense

duration $(t=12.6, \mathrm{df}=93, \mathrm{p}=0.0001)$ were all significantly greater on long trips than short trips. There was no difference in elongation coefficient between short and long trips $(t=1.5, \mathrm{df}=93, \mathrm{p}=0.14)$. Correlation analysis showed that longer foraging trips had a greater range $(\mathrm{r}=0.879, \mathrm{p}=0.0001)$ and distance travelled $(r=0.961, p=0.0001)$. There were also differences in trip characteristics between the guard and crèche periods of chick rearing. Range $(t=2.21$, $\mathrm{p}=0.0296, \mathrm{df}=93)$ and elongation coefficient $(t=6.10$, $\mathrm{p}<0.001$ ) were both greater during the crèche period than during the guard period. Distance travelled $(t=0.82, \quad \mathrm{p}=0.4148)$ and trip duration $(t=0.69$, $\mathrm{p}=0.5478$ ) did not differ between the guard and the crèche periods of chick rearing.

\section{Sex differences and inter-annual differences in chick-rearing foraging trips}

Sex and interannual differences in trip characteristics were investigated with ANOVAs on transformed trip parameters. Distance did not differ between the 2 years $\left(F_{1,91}=1.29, \mathrm{p}=0.26\right)$ or sexes $\left(F_{1,91}=1.27\right.$, $\mathrm{p}=0.26)$, although the interaction between sex and year was significant $\left(F_{1,91}=8.34, \mathrm{p}=0.005\right)$, suggesting that distances travelled by the 2 sexes differed between years (Fig. 6). Range did not differ between the 2 years $\left(F_{1,91}=1.14, \mathrm{p}=0.29\right)$, but differed between sexes $\left(F_{1,91}=4.25, \mathrm{p}=0.042\right.$; Fig. 6$)$. The interaction between sex and year was also significant $\left(F_{1,91}=17.8\right.$, $\mathrm{p}=0.0001$ ), again suggesting that the sexes differed between years. Elongation coefficient did not differ between years $\left(F_{1,91}=0.74, \mathrm{p}=0.39\right)$ but differed significantly between sexes $\left(F_{1,91}=18.0, \mathrm{p}=0.0001\right.$; Fig. 6). Again the interaction term was significant $\left(F_{1,91}=35.9, \mathrm{p}=0.0001\right)$. Trip duration did not differ between years $\left(F_{1,91}=2.44, \quad \mathrm{p}=0.12\right)$ or sexes $\left(F_{1,91}=0.01, \mathrm{p}=0.99\right)$ and the interaction between year and sex was not significant $\left(F_{1,91}=2.61, \mathrm{p}=0.11\right.$; Fig. 6). Differences in the foraging ranges of male and female penguins are shown by the density distributions of locations recorded during all chick-rearing foraging trips (Fig. 7). The distributions suggest that in contrast to males, females show less variation in overall range, but a greater tendency to forage intensively in more distant areas associated with the shelf edge. 

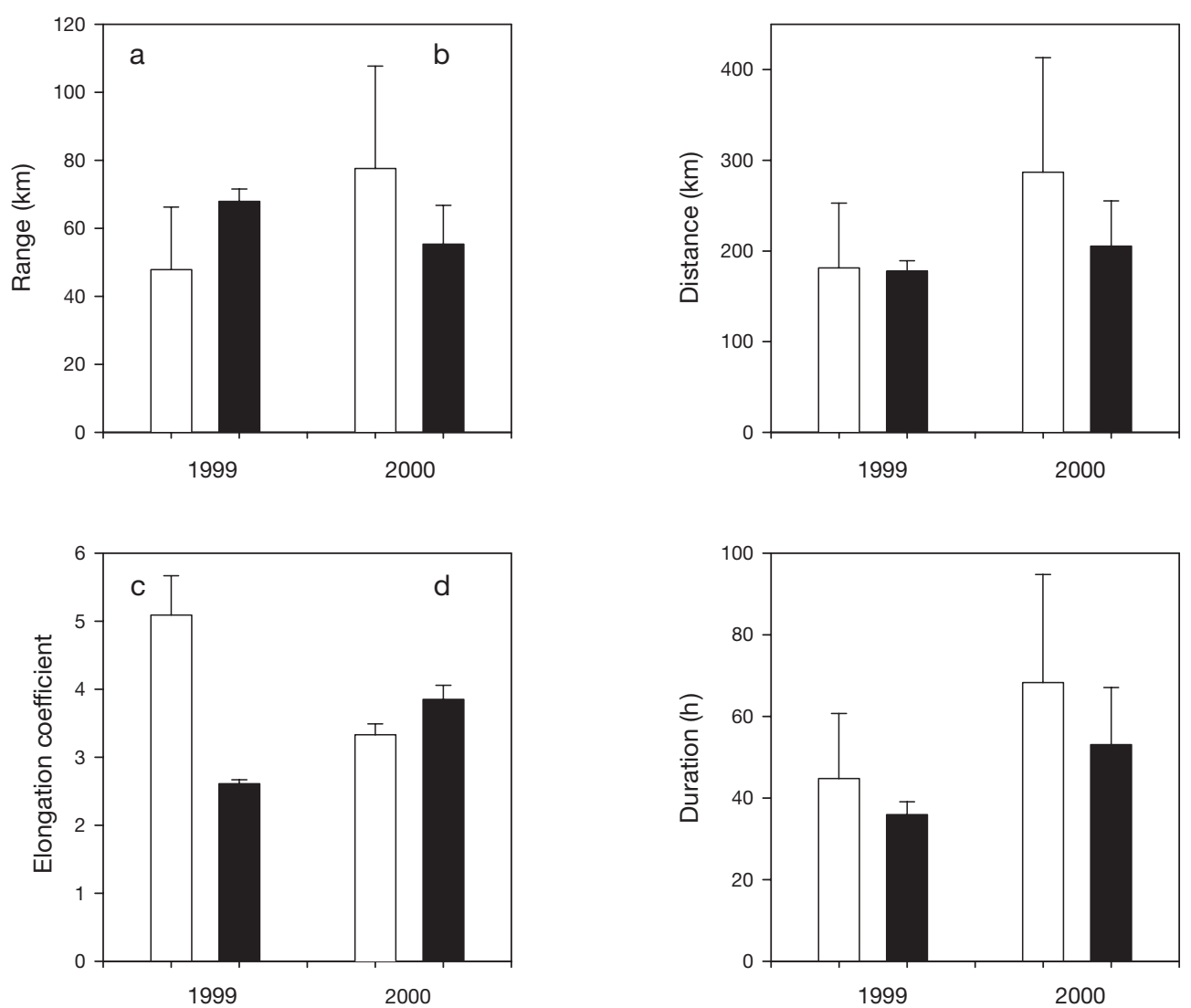

Fig. 6. Eudyptes chrysolophus. Foraging trip parameters during chick-rearing period. Graphs show mean (+SE) of (a) range, (b) distance, (c) elongation coefficient, and (d) trip duration of trips made by males (white bars) and females (black bars) during chick-rearing periods of 1999 and 2000
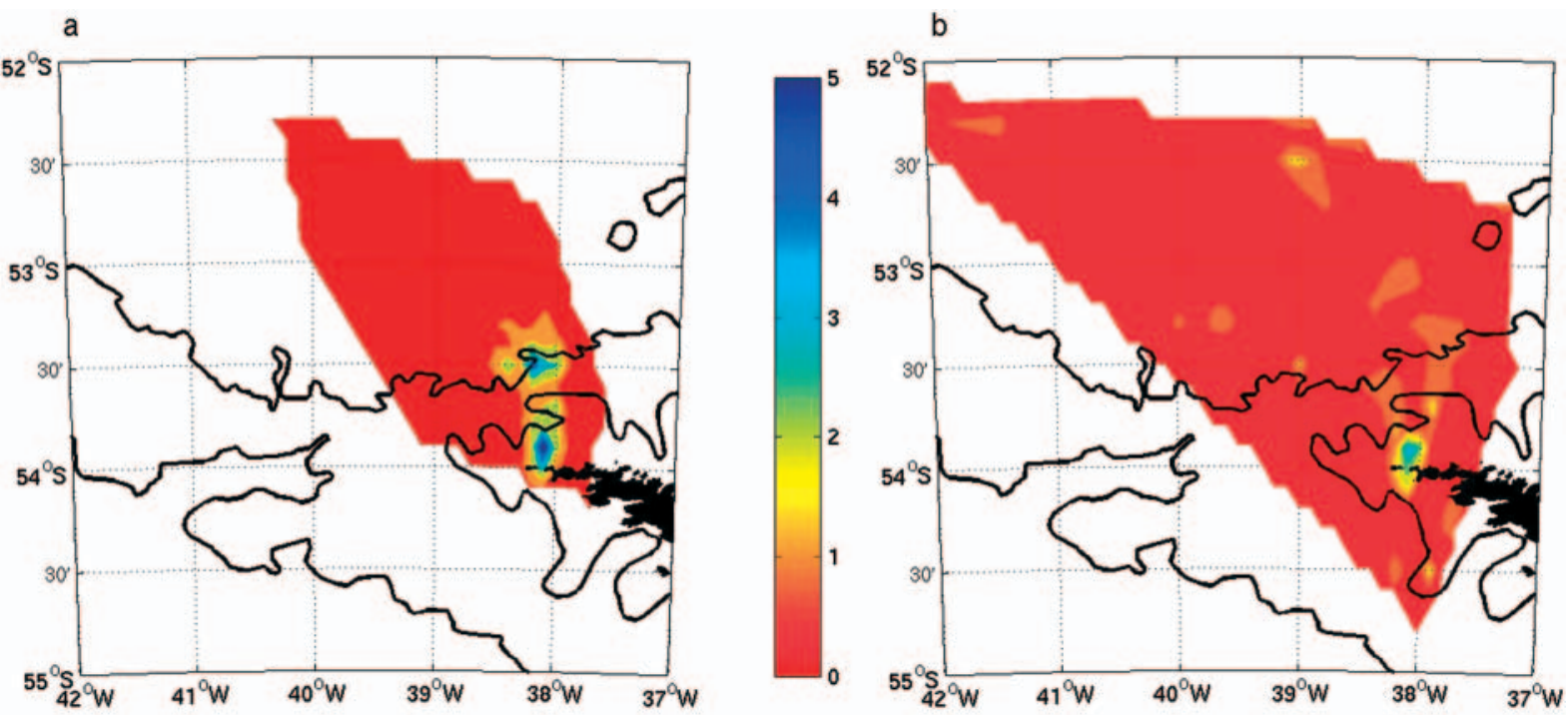

Fig. 7. Eudyptes chrysolophus. Density distributions of females (a) and males (b) during chick-rearing periods of 1999 and 2000. Maps show South Georgia and the 200 and $2000 \mathrm{~m}$ bathymetric contour lines. Density distributions are constructed from contour plots of 5 contours with a linear spline interpolation. Red represents the least dense areas, blue the most dense 


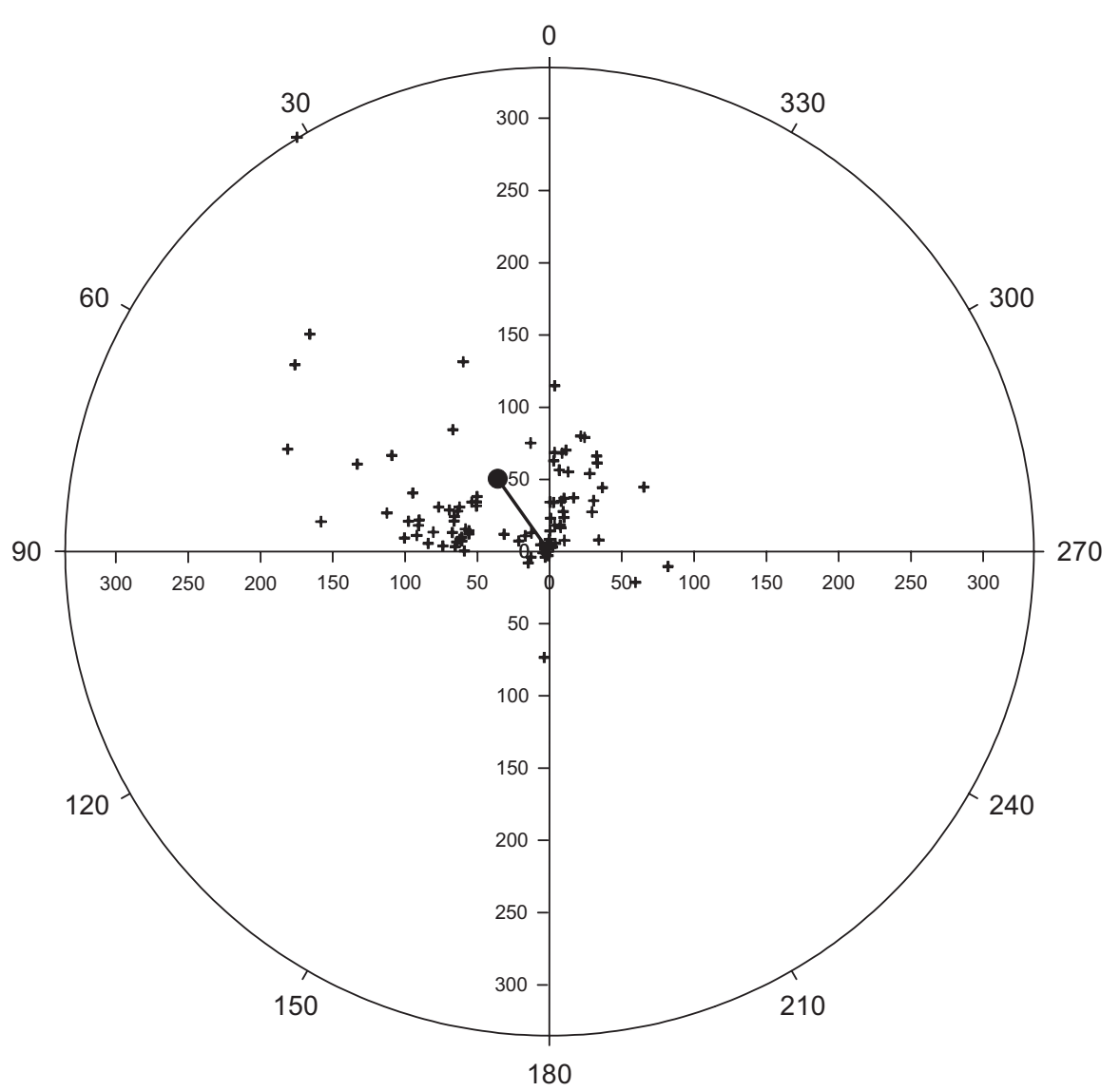

Fig. 8. Eudyptes chrysolophus. Circular plot showing the bearings of all chick-rearing foraging trips made during 1999 and 2000 $(\mathrm{n}=95)$. Each cross represents the angle $\left(0\right.$ to $\left.360^{\circ}\right)$ and range $(\mathrm{km})$ of 1 foraging trip, black circle and solid line the mean range and angle of all chick-rearing foraging trips

\section{Inter- and intra-individual variation in chick-rearing foraging trips}

The bearings of all chick-rearing foraging trips are shown in Fig. 8. The mean angle of a foraging trip from Bird Island was $35.5^{\circ} \mathrm{W}$ (angular deviation $50.3^{\circ} \mathrm{W}$ ), i.e. in approximately a north westerly direction from Bird Island (i.e. at a bearing of $324.5^{\circ}$ ). The Watson $U^{2}$ goodness-of-fit test for circular data (Zar 1984) showed that the bearings of foraging trips made by macaroni penguins were not randomly distributed from Bird Island ( $\mathrm{df}=0.614, \mathrm{p}<0.001$ ). Three or more foraging trips were recorded from 14 penguins during chick rearing. ANOVA showed that there were no significant differences between bearings of foraging trips made by different individuals $\left(F_{13,46}=1.29, \mathrm{p}=0.268\right)$ and the coefficient of variation within individuals was very high (1.9). The coefficient of variation between individuals was also high (1.1). There was a significant correlation between bearing and range of a foraging trip $(\mathrm{r}=0.234, \mathrm{n}=73, \mathrm{p}=0.046)$; penguins that travelled on more westerly bearings from Bird Island travelled further than those on more easterly bearings.

\section{DISCUSSION}

\section{Potential biases associated with satellite-tracking data and instrument effects}

There are several potential biases that must be taken into account during the interpretation of satellitetracking data. (1) The number of locations recorded can vary with the time of day due to the positions of the satellite (e.g. Georges et al. 1997). (2) For diving animals including penguins, diving activity can affect the number of locations recorded as the animal has to be at the surface for a certain time before an accurate location can be made. The few locations recorded during the middle of the day in this study have also been reported in other studies (e.g. Jouventin et al. 1994, Kerry et al. 1995, Georges et al. 1997, Hull et al. 1997) and may be due to either or both of the above factors. However, biases from these sources are unlikely to affect any of our comparisons between years, seasons and sexes. Additionally, because very few uplinks $(<3)$ were recorded from some foraging trips during chick rearing ( $26 \%$ of trips), they were not included in the analysis of trip parameters. The trip 
parameters may therefore be slight overestimates, as some short trips were excluded. Conversely, because fewer uplinks were recorded in the middle of the day, the main period of foraging for many trips, the distances travelled and range may have been underestimated on some trips, particularly short trips of $<24 \mathrm{~h}$ (40\% of trips analysed). (3) The devices themselves may affect the foraging behaviour of the birds, attached instruments potentially causing increased drag resulting in longer foraging trips, reduced swimming speed and lower food intake (e.g. Wilson et al. 1986, Gales et al. 1990, Culik \& Wilson 1991, Kerry et al. 1995, Bost et al. 1997, Guinet et al. 1997, Hull et al. 1997).

In our study, the satellite transmitters used were relatively large (compared to those available nowadays), albeit still just below the threshold value of $5 \%$ of body mass, above which significant disturbance to behaviour may occur. The drag associated with these devices was probably responsible for foraging trips during incubation being longer than those of control birds, presumably because instrumented birds took longer to travel to the preferred feeding areas. Nevertheless there were no detectable effects on breeding performance during the long incubation trips (similar to results from a study of king penguin Aptenodytes patagonicus by Guinet et al. 1997). Effects on chickrearing performance, when instrument deployments were brief (rarely more than 1 trip) were also either negligible or absent. Furthermore, any instrumentrelated biases should be similar and consistent in all the comparative aspects of our study.

\section{Comparison between incubation and chick-rearing foraging trips}

This study provides the first records of foraging areas used by macaroni penguins during the foraging trips between incubation shifts. Trip durations reported in this study were slightly longer compared to the average of $12.7 \mathrm{~d}$ for males and $11.1 \mathrm{~d}$ for females reported by Williams \& Croxall (1991). Sample sizes were too small to compare these trip durations statistically. Male and female penguins travelled far from Bird Island in a northwesterly direction towards the PF and MEB. Males travelled further than females, their foraging trips were longer and they spent more time beyond the $\mathrm{PF}$ than females. It is possible that the higher travel speeds found during the day than night in 2000 reflect much time spent commuting over the distances covered on these foraging trips, although the same relationship was not found in the following year.

The foraging ranges of macaroni penguins, particularly males, during the incubation trips, cover areas both south and north of the Polar Front (PF), taking them into the waters of the Polar Frontal Zone (PFZ) south of the Subantarctic Front (SAF). There is some debate about the position of the PF around this area and whether it lies to the north or the south of the MEB (e.g. Whitworth et al. 1991, Gille 1994, Orsi et al. 1995), the more recent detailed studies suggesting that it lies to the south (Moore et al. 1997, 1999, Trathan et al. 1997, 2000). If this is the case, most of the penguins tracked during the incubation stage of the breeding season in our 2 years of this study foraged in the PFZ. This has significant implications for the food available to the penguins at this time, as the nature and availability of prey will be different to the north and south of the PF (Cooper et al. 1990, Atkinson et al. 2001). During chick rearing, macaroni penguins feed mainly on krill (Croxall \& Prince 1980), but their diet during the incubation period is unknown. The diets of king and royal penguins Eudyptes schlegeli foraging in the Indian Ocean sector of the PFZ both contained significant quantities of myctophid fishes (Bost et al. 1997, Hull 1999). Myctophids and cephalopods are equally characteristic of the PFZ to the north of South Georgia (e.g. Hulley 1990, Rodhouse et al. 1996) and may well form an important part of the diet of the macaroni penguin at this time.

In contrast to incubation foraging trips, trips during the chick-rearing period covered a much smaller range and birds stayed mainly over the continental shelf of South Georgia. The average distance reached from Bird Island during chick-rearing foraging trips $(62.1 \mathrm{~km})$ was greater than that calculated from estimates using at-sea distribution data. Croxall et al. (1984) used data on trip duration and travel speed to estimate that most foraging trips took macaroni penguins between 90 and $120 \mathrm{~km}$ from Bird Island. After allowing for time spent diving, this estimate was later re-calculated as $43 \mathrm{~km}$ (Trathan et al. 1998). The average range of a foraging trip was estimated at $45 \mathrm{~km}$ from at-sea distribution data (Trathan et al. 1998). The first estimate is greater than and the latter 2 estimates less than the average distance travelled as measured from our satellite-tracking data. It is possible, however, that our estimate is slightly high, as some very short trips were not included in the analysis of foraging trip parameters due to small sample sizes of satellite locations. We suggest that most foraging by macaroni penguins during the chick-rearing period takes place within 50 to $60 \mathrm{~km}$ of Bird Island.

There were some differences in the characteristics of short and long foraging trips during chick rearing. Penguins on long trips ( $>24 \mathrm{~h}$ in duration) did not simply spend more time in a foraging area, but travelled longer distances and further from Bird Island than penguins on short trips. There was no difference in the elongation coefficients between these 2 trip types, however, suggesting that perhaps foraging strategy did not differ much between these 2 trip types. 
Short and long trips were undertaken during both the guard and crèche stages of the chick-rearing period. The longer range and greater elongation coefficient of crèche stage trips compared to guard stage trips may reflect slight sex differences in foraging trip parameters, as males only forage during the crèche period of chick rearing. The differences found in trip parameters between short and long trips were more pronounced than the differences seen between the guard and crèche periods of chick rearing.

The differences in calculated travel speeds during the day and night between incubation and chick-rearing foraging trips probably reflect the differences in the duration of trips and the distance travelled during trips in these different stages of the breeding cycle. In comparison, no difference in travel speeds between different stages of the breeding season was found in royal penguins, but foraging trip durations during chick rearing were longer (Hull et al. 1997). Calculated travel speeds were lower than the average speed of 7.5 $\mathrm{km} \mathrm{h}^{-1}$ estimated for macaroni penguins by Brown (1987). Rates of travel calculated from satellite-tracking data are on a coarse scale, as small-scale changes in foraging behaviour are often not detected (Hull et al. 1997). Kerry et al. (1995) also found that travel speeds of the Adelie penguin Pygoscelis adeliae estimated from satellite-tracking data were less than measured swim speeds using other methods. These differences can probably be accounted for by differences in travelling speed and actual swim speed; estimates from satellite-tracking data alone are always of travelling speed (Culik \& Luna-Jorquera 1997).

The vast differences in foraging areas and habitat used by macaroni penguins between the incubation and chick-rearing periods may be explained, at least in part, by their differing requirements during these stages of the breeding season. During incubation, penguins need to restore body reserves lost during fasting and/or to prepare for mass loss during fasting; however, they have a relatively long time in which to do this, and therefore the potential to travel significant distances. During chick rearing, penguins are constrained by the need to provide regular meals for their offspring, in addition to maintaining their own body condition, and therefore travel shorter distances from their breeding colony. King penguins also forage at distances further from their breeding colony during incubation than during chick rearing (Guinet et al. 1997). The seasonal differences in foraging range suggest that, at least early in the breeding season, macaroni penguins choose to travel to or towards the PFZ rather than foraging over the shelf water surrounding South Georgia, to which they are essentially confined during the chick-rearing period.

\section{Differences between sexes}

There were some differences in foraging trip characteristics between male and female penguins, both during incubation and chick rearing. Differences between sexes may be expected in this size-dimorphic species that shows unequal division of labour during the chick-rearing period. During incubation, males travelled further on their longer foraging trips than females. On incubation trips, males have to recover from one long fast and prepare for a second one; in contrast, females have to recover from one fast and prepare for feeding their chick. These sex-related differences in breeding duties, particularly the need to prepare for provisioning offspring, may constrain the foraging areas available to females compared to males.

During chick rearing, across all trips, females travelled slightly further than males on average (female mean range $=63.2 \mathrm{~km}$, male mean range $=59.3 \mathrm{~km}$ ), but there was much greater variation in the foraging range of males than females. This is reflected in the larger overall area of the foraging distribution of males compared with females (Fig. 6).

\section{Interannual differences}

The foraging ranges of macaroni penguins were very similar during the chick-rearing periods of the 2 years studied. There were no differences in foraging trip characteristics between the 2 years and the foraging distributions did not differ significantly (Barlow et al. 2002). It might be expected that interannual differences in foraging ranges reflect interannual variation in prey availability. In the 2 years of study, estimated krill biomass in the South Georgia area was similar, and low (1999: $12.03 \mathrm{gm}^{-3}$, Brierley \& Goss 1999; 2000: $12.26 \mathrm{gm}^{-3}$, AtlantNIRO/British Antarctic Survey unpubl. data) and the proportion of krill in the diets of macaroni penguins was also low (1999: 35.9\%; 2000: $15.6 \%$; Barlow et al. 2002). As prey availability was estimated to be very similar in the foraging areas of macaroni penguins in the 2 years of study, it is not unexpected that their foraging ranges were very similar. However, both these years were somewhat unusual in their low estimated krill biomass at South Georgia (e.g. Brierley et al. 1997); foraging ranges in years of higher krill biomass might differ.

\section{Inter-individual differences}

The non-random distribution of bearing of foraging trips has been recorded in several species of penguin (e.g. Hunt et al. 1992, Bost et al. 1997, Hull et al. 1997). 
The distribution of macaroni penguins found in this study is not consistent with the more radial distribution derived from at-sea observations of macaroni penguins around South Georgia (Trathan et al. 1998). However, penguins were only tracked from 1 colony in our study and it is possible that there is some separation in foraging areas between nearby colonies, e.g. those of the very large colonies on the Willis Islands (Prince \& Poncet 1996). Although the distribution of the direction taken during foraging trips was not random, individuals did not use similar bearings on consecutive trips. The variation within individuals was similar to that between individuals, suggesting that individual birds did not have preferences for particular directions, or choose a bearing based on that of the previous foraging trip. It is possible, however, that in years of high krill density there would have been more evidence for similar trajectories in successive foraging trips. In years of low food availability, birds are presumably more likely to prospect in new and different directions.

\section{CONCLUSIONS}

This study has provided the first detailed data on the foraging areas used by macaroni penguins during the breeding season. It has allowed an investigation of potential differences in foraging area due to stage of the breeding season, sex, year and individual.

Under the prevailing circumstances, of relatively similar and low densities of krill in both years, we found little evidence of significant interindividual or interannual variation. However we did find relatively small, but consistent, differences between sexes, suggesting that differences in size (in this the most sexually size-dimorphic of penguins), together with differences in the timing and nature of breeding duties, may result in the sexes exploiting different (but overlapping) areas during chick rearing. A critical test of this hypothesis would be during the pre-moult period when both sexes are foraging simultaneously and are similarly unconstrained by the demands of offspring.

The main difference our study revealed was that, in contrast to ranges during the chick-rearing period, which were essentially confined to the South Georgia shelf, ranges during incubation were many times larger and involved travel to more distant areas. These areas included the waters of the PFZ, suggesting that birds were targeting this potentially highly productive area, where a diverse selection of prey, including Antarctic krill, may be found. If macaroni penguins choose to forage in these distant areas when unconstrained by the need to provision offspring, this sug- gests that during the winter, when they are not seen in the immediate vicinity of South Georgia, they are likely to be found at or north of the APFZ. This has potentially important implications for estimates of the distribution and amount of energy consumed by macaroni penguins and for assessments of overlap with the commercial fishery for krill, which at South Georgia occurs mainly in winter and over shelf and shelf-slope areas.

This reinforces the importance of obtaining data on the distribution of macaroni penguins during their post-breeding season, together with the need to compare the results of our study with similar work undertaken during years of greater krill abundance.

Acknowledgements. We thank all members of the Bird Island team, particularly Jane Tanton, who helped with fieldwork and deployment of instruments, and Ian Boyd for help with data analysis. We are grateful for the thoughtful and constructive comments of 4 reviewers.

\section{LITERATURE CITED}

Atkinson A, Whitehouse MJ, Priddle J, Cripps GC, Ward P, Brandon MA (2001) South Georgia, Antarctica: a productive, cold water, pelagic ecosystem. Mar Ecol Prog Ser 216:279-308

Barlow KE, Croxall JP (2002) Provisioning behaviour of macaroni penguins Eudyptes chrysolophus. Ibis 144:248-258

Barlow KE, Boyd IL, Croxall JP, Reid K, Staniland IJ, Brierley AS (2002) Are penguins and seals in competition for Antarctic krill at South Georgia? Mar Biol 140:205-213

Bost CA, Georges JY, Guinet C, Cherel Y, Putz K, Charrassin JB, Handrich Y, Zorn T, Lage J, Le Maho Y (1997) Foraging habitat and food intake of satellite-tracked king penguins during the austral summer at Crozet Archipelago. Mar Ecol Prog Ser 150:21-33

Boyd IL, McCafferty DJ, Reid K, Taylor R, Walker TR (1998) Dispersal of male and female Antarctic fur seals (Arctocephalus gazella). Can J Fish Aquat Sci 55:845-852

Brierley AS, Goss C (1999) Acoustic estimates of krill density at South Georgia, Dec/Jan 1998/99. WG-EMM-99/20. CCAMLR Sci (Abstracts) 1999:9

Brierley AS, Watkins JL, Murray AWA (1997) Interannual variability in krill abundance at South Georgia. Mar Ecol Prog Ser 150:87-98

Brown CR (1987) Travelling speed and foraging range of macaroni and rockhopper penguins at Marion Island. J Field Ornithol 58:118-125

Clarke BD, Bemis W (1979) Kinematics of swimming of penguins at the Detroit zoo. J Zool (Lond) 188:411-428

Cooper J, Brown CR, Gales RP, Hindell MA, Klages NTW, Moors PJ, Pemberton D, Ridoux V, Thompson KR (1990) Diets and dietary segregation of crested penguins (Eudyptes). In: Davis LS, Darby JT (eds) Penguin biology. Academic Press, San Diego, p 131-156

Croxall JP (1984) Seabirds. In: Laws RM (ed) Antarctic ecology. Academic Press, London, p 533-619 
Croxall JP, Lishman GS (1987) The food and feeding ecology of penguins. In: Croxall JP (ed) Seabirds feeding ecology and role in marine ecosystems. Cambridge University Press, Cambridge, p 101-131

Croxall JP, Prince PA (1980) Food, feeding ecology and ecological segregation of seabirds at South Georgia. Biol J Linn Soc 14:103-131

Croxall JP, Prince PA (1987) Seabirds as predators on marine resources, especially krill, at South Georgia. In: Croxall JP (ed) Seabirds feeding ecology and role in marine ecosystems. Cambridge University Press, Cambridge, p 347-368

Croxall JP, Ricketts C, Prince PA (1984) Impact of seabirds on marine resources, especially krill, of South Georgia waters. In: Whittow GC, Rahn H (eds) Seabird energetics. Plenum Press, New York, p 285-317

Croxall JP, Briggs DR, Kato A, Naito Y, Watanuki Y, Williams TD (1993) Diving pattern and performance in the macaroni penguins Eudyptes chrysolophus. J Zool (Lond) 230: $31-47$

Croxall JP, Prince PA, Reid K (1997) Dietary segregation in South Georgia seabirds. J Zool (Lond) 242:531-556

Culik BM, Luna-Jorquera G (1997) Satellite tracking of Humboldt penguins (Spheniscus humboldti) in northern Chile. Mar Biol 128:547-556

Culik BM, Wilson RP (1991) Swimming energetics and performance of instrumented Adelie penguins (Pygoscelis adeliae). J Exp Biol 158:355-368

Culik BM, Bannasch R, Wilson RP (1994) External devices on penguins: how important is shape? Mar Biol 118: $353-357$

Gales RP, Williams C, Ritz D (1990) Foraging behaviour of the Little penguin, Eudyptula minor: initial results and assessment of instrument effect. J Zool (Lond) 220:61-85

Georges J Y, Guinet C, Jouventin P, Weimerskirch H (1997) Satellite tracking of seabirds: interpretation of activity pattern from the frequency of satellite locations. Ibis 139:403-405

Gille ST (1994) Mean sea surface height of the Antarctic Circumpolar Current from Geosat data: method and application. J Geophys Res 99:18255-18273

Green K, Williams R, Green MG (1998) Foraging ecology and diving behaviour of macaroni penguins Eudyptes chrysolophus at Heard Island. Mar Ornithol 26:27-34

Guinet C, Koudil M, Bost CA, Curbec JP, Georges JY, Mouchot MC, Jouventin P (1997) Foraging behaviour of satellite-tracked king penguins in relation to sea-surface temperatures obtained by satellite telemetry at Crozet Archipelago, a study during three austral summers. Mar Ecol Prog Ser 150:11-20

Hull CL (1999) Comparison of the diets of breeding Royal Eudyptes schlegeli and rockhopper E. chrysocome penguins at Macquarie Island over three years. J Zool (Lond) 247:507-529

Hull CL, Hindell MA, Michael K (1997) Foraging zones of royal penguins during the breeding season, and their association with oceanographic features. Mar Ecol Prog Ser 153:217-228

Hulley PA (1990) Family Myctophidae. In: Gon O, Heemstra PC (eds) Fishes of the Southern Ocean. JLB Smith Institute of Ichthyology, Grahamstown, p 146-178

Hunt GL Jr, Heinemann D, Everson I (1992) Distributions and predator-prey interactions of macaroni penguins, Antarctic fur seals, and Antarctic krill near Bird Island, South Georgia. Mar Ecol Prog Ser 86:15-30

Jouventin P, Capdeville D, Cuenot-Chaillet F, Boiteau C (1994) Exploitation of pelagic resources by a non- flying seabird: satellite tracking of the king penguin throughout the breeding season. Mar Ecol Prog Ser 106:11-19

Kerry KR, Clarke JR, Else GD (1995) The foraging range of Adelie penguins at Bechervaise Island, Mac Robertson Land, Antarctica as determined by satellite telemetry. In: Dann P, Norman I, Reilly P (eds) The penguins: ecology and management. Surrey Beatty \& Sons, Chipping Norton, p 216-243

Kooyman G, Hull C, Olsson O, Robertson G, Croxall J, Davis L (1999) Foraging patterns of polar penguins. In: Adams NJ, Slotow RH (eds) Proc 22 Int Ornithol Cong, Durban. Birdlife South Africa, Johannesburg, p 2021-2039

Moore JK, Abbott MR, Richman JG (1997) Variability in the location of the Antarctic Polar Front (90E-20EW) from satellite sea surface temperature data. J Geophys Res 102:27825-27833

Moore JK, Abbott MR, Richman JG (1999) Location and dynamics of the Antarctic Polar Front from satellite sea surface temperature data. J Geophys Res 104:3059-3073

Orsi AH, Whitworth T III, Nowlin WD Jr (1995) On the meridional extent of the Antarctic Circumpolar Current. Deep-Sea Res Part I 42:641-673

Prince PA, Poncet S (1996) South Georgia bird distributions. In: Trathan PN, Daunt FHJ, Murphy EJ (eds) South Georgia: an ecological atlas. British Antarctic Survey, Cambridge, Section 2: maps 2.1-2.33

Rodhouse PG, Prince PA, Trathan PN, Hatfield EMC, Watkins JL, Bone DG, Murphy EJ, White MG (1996) Cephalopods and mesoscale oceanography at the Antarctic Polar Front: satellite tracked predators locate pelagic trophic interactions. Mar Ecol Prog Ser 136:37-50

Stahl JC, Jouventin P, Mougin JL, Roux JP, Weimerskirch H (1985) The foraging zones of seabirds in the Crozet Island sector of the Southern Ocean. In: Siegfried WR, Condy WR, Laws RM (eds) Antarctic nutrient cycles and food webs. Springer-Verlag, Berlin, p 478-486

Stokes DL, Boersma PD, Davis LS (1998) Satellite tracking of Magellanic penguin migration. Condor 100:376-381

Trathan PN, Brandon MA, Murphy EJ (1997) Characterisation of the Antarctic Polar Frontal Zone to the north of South Georgia in summer 1994. J Geophys Res 102:10483-10497

Trathan PN, Murphy EJ, Croxall JP, Everson I (1998) Use of at-sea distribution data to derive potential foraging ranges of macaroni penguins during the breeding season. Mar Ecol Prog Ser 169:263-275

Trathan PN, Brandon MA, Murphy EJ (2000) Transport and structure within the Antarctic Circumpolar Current to the north of South Georgia. Geophys Res Lett $27: 1727-1730$

Trivelpiece WZ, Trivelpiece SG, Volkman NJ (1987) Ecological segregation of Adelie, gentoo and chinstrap penguins at King George Island, Antarctica. Ecology 68:351-361

van Franeker JA (1994) A comparison of methods for counting seabirds at sea in the Southern Ocean. J Field Ornithol 65:96-108

Veit RR, Silverman ED, Everson I (1993) Aggregation patterns of pelagic predators and their principal prey, Antarctic krill, near South Georgia. J Anim Ecol 62:551-564

Whitworth III T, Nowlin Jr WD, Pillsbury RD, Moore MI, Weiss RF (1991) Observations of the Antarctic Circumpolar Current and deep boundary current in the southwest Atlantic. J Geophys Res 96:15105-15118

Williams TD, Croxall JP (1991) Annual variation in breeding 
biology of macaroni penguins, Eudyptes chrysolophus, at Bird Island, South Georgia. J Zool (Lond) 223:189-203

Wilson RP, Grant WS, Duffy DC (1986) Recording devices on free-ranging animals: does measurement affect foraging performance? Ecology 67:1091-1093

Wilson RP, Putz K, Peters G, Culik B, Scolaro AJ, Charrassin JB, Ropert-Coudet Y (1997) Long-term attachment of

Editorial responsibility: Otto Kinne (Editor),

Oldendorf/Luhe, Germany transmitting and recording devices to penguins and other seabirds. Wildl Soc Bull 25:101-106

Woehler EJ (1993) The distribution and abundance of Antarctic and Subantarctic penguins. Scientific Committee on Antarctic Research (SCAR), Cambridge

Zar JH (1984) Biostatistical analysis, 2nd edn. Prentice-Hall, Englewood Cliffs, NJ

Submitted: March 30, 2001; Accepted: October 9, 2001

Proofs received from author(s): April 8, 2002 